\title{
Success Factors of Online Learning Videos
}

\author{
http://dx.doi.org/10.3991/ijim.v9i4.4460 \\ Safak Korkut, Rolf Dornberger, Prajakta Diwanji, Bindu Puthur Simon and Michael Märki \\ University of Applied Sciences and Arts Northwestern Switzerland FHNW, Basel, Switzerland
}

\begin{abstract}
Videos have emerged as a dominant medium for educational purposes in many Massive Open Online Course (MOOC) platforms. Online learning videos are visual components of the online learning platforms. They are particularly interesting for students who are visual learners and who learn best by watching the short format engaging videos rather than by just reading or listening to course materials. The paper focuses on the categorization of factors that are responsible for the success/popularity of online learning videos. The research is based on the literature review and video observations of the MOOC platforms, in particular of the Khan Academy and Coursera. In this paper, we propose a tabular and a spider graph as a condensed overview of categories that should commonly be utilized by the online learning video production to make them successful.
\end{abstract}

Index Terms-Online learning videos, massive open online course, MOOC, video production, e-learning.

\section{INTRODUCTION}

\section{A. Background Information}

E-learning has become the significant trend in education and aims offering a common platform that provides educational material, tools and services to create and deliver training in an effective and economical way. Video is a rich and powerful medium in e-learning. Recent developments in multimedia and Internet technologies have resulted in powerful systems with instructional video components [1] [2]. Many students find video-based courses more natural, easier and clearer than text-based courses. Students' opinion is "video communication is required for each online course because it is helpful in every way" [3] Recent efforts of organizations like edX, Udacity, Coursera and Khan Academy have produced thousands of educational videos with millions of views to make high quality teaching available to the masses all across the globe [4].

The online learning videos are the visual components of MOOC platforms. By definition a MOOC is a "massive open online course" which is Internet based and "usually free", "credit-less" and "massive" [5]. The MOOCs have been here for a few years. In 2006 the first MOOC that reached well over 100,000 people over the course of the year 2006-2007 was run; in 2008, Stephen Downes and George Siemens created an online course to prove that you could do connectivist open learning via online learning digital platforms [6]. The year 2012 was called the year of the MOOC where new platforms like Coursera, Udacity and edX emerged. These platforms provide instructor based online videos combined with assessments and interactive demos.

MOOCs provide learning videos, readings, problem sets and forums that help build a community for students, professors and teaching assistants. The course design focuses on presentation and interactivity. The MOOC platform is a combination of education, entertainment and social networking. The medium of teaching is video lecture. The MOOC platforms let you pause the videos and take the quiz to make sure you understand the material. There is immediate feedback. There are forums and discussion boards. They may have homework and final exam [5]. These video based courses are sometimes called xMOOC [7].

One of the popular online learning platforms focussed on in this paper is Khan Academy [12]. The Khan Academy owner Salman Khan started recording educational tutoring videos and posting them on YouTube in 2006 so his family members could watch them and learn the subjects on their own. More and more people started watching these videos on YouTube and Khan Academy came into existence in 2006. Khan Academy created an educational website that showcased free online learning videos for students all over the world. It has thousands of micro lectures via tutorials stored on YouTube that belong to a wide range of academic videos mostly in mathematics and sciences [8] [9].

\section{B. Popularity of the Online Learning Videos}

Since their existence the MOOC platforms and online learning platforms have attracted massive audience. edX and Coursera claim almost four and half million of enrolees [10]. In a recent study done by researchers on edX platform it was found that students were engaged in watching the videos most of their time [10] [7]. Study of three Coursera courses revealed that many student watched primarily the videos and skipped online discussions and other interactive components [7]. In June 2014, Khan Academy's YouTube channel shows 1499 videos, 1,753,978 subscribers and over 300 million views [11]. They record up to 1 million users in a month who watch on an average 200,000 videos per day [12]. Khan Academy's online videos are used by many schools from around the world to teach the students difficult maths concepts [8].

\section{Purpose of Study, Research Objectives}

There are many factors that make the videos compelling to the audience. As these videos are a significant part of $\mathrm{MOOC}$, the content providing organizations spend a lot of money, time and effort for video production and maintenance. Videos are a time consuming medium to produce and cannot be easily modified once produced [4].These videos are often filmed in diverse styles and media requires production resources and therefore strategizing the best possible methods to allocate the resources [13]. Restructuring a video into shorter segments requires lot of thinking and efforts. It takes many hours to produce one hour of quality video [14]. One hour of video might take somewhere between 5-20 hours depending on the accuracy 
of the script, how the b-rolls were handled and many other variables from sound to visuals that have an effect on the production cycle.

Online learning videos are hosted on platforms like YouTube and MOOC websites. Apart from video production factors there are external factors related to technology, and social media that can influence the views of these learning videos. The identification and classification of factors that affect video views can help engineers and instructional designers to effectively design and manage online learning videos.

\section{Research Questions}

This paper deals with the following research questions: To what extent is it possible to categorize the factors related to the success of online learning videos of MOOC and how to formulate them in a condensed overview?

Factors related to the success of online learning video have been taken into consideration independently with the aim to reach at a visualization of the factors. Furthermore, the research team has the intention to underline the necessities for the engineers, designers and video producers to help design and manage online learning videos.

\section{E. Research Design and Structure of the Paper}

The paper consists of the following sections that provide the research design to answer the research question.

1) Literature review: Identification of the broad factors related to success of online learning videos from research papers, MOOC websites and articles.

2) Research Methodology: Selection and description of the suitable research design.

3) Suggestions/New development: Organization of the factors based on the literature review and observations.

4) Evaluation: Evaluation of the suggestions/development.

5) Conclusion: Findings, discussion of new knowledge.

6) Shortcomings and Further Study: Drawbacks of the findings and suggestions for further study.

\section{LiterATURE REVIEW AND OBSERVATIONS}

In this section, the main focus is on the qualitative analysis of the factors affecting the video views and the engagement of the online learning videos. The points are studied from research papers, articles and MOOC websites. For easy understanding they are referred to as the success factors of online learning videos.

\section{F. Metrics to Measure Success of Videos}

Following [17], the success of videos is defined by the number of video views. Most popular videos have views ranging from one million and above in a given period of time. However, the average time spent by the user on videos, i.e. the engagement time, also determines the popularity of the videos. Success/popularity of the videos can be measured by the metrics given by YouTube and other video distribution platforms [18] [19]. For instance, YouTube provides the following metrics:

1) Performance: Views, estimated minutes watched, subscribers.
2) Engagement: Audience retention, likes, dislikes comments, shares, and favourites.

3) Demographics: Top geographies, by gender.

4) Discovery: Top playback locations, top traffic sources.

\section{G. Factors Related to Video Style}

Research was done to study which video type is best liked by students in MOOC. The research paper by Philip Guo, Juho Kim and Rob Robin "How video production affects student engagement" discusses the factors related to the production of the learning videos [7]. The paper presents an empirical study of students' engagement with MOOC videos as measured by how long students are watching the video and if they attempt to take other materials like assessments, quizzes, etc. Engagement is time spent by users on watching the video. Video providers like YouTube use video engagement as an important metric to measure user satisfaction [18]. Research was done on papers of four edX courses in fall 2012 and data related to the engagement styles of videos, video watching sessions of students related to play, pause and resume actions was collected. To extract the video logs edX servers were mined for data. The research was performed on 6.9 million total video watching sessions across four courses.

After analysing the data the following conclusions were made in the paper [7].

- Shorter videos are more engaging. Shorter videos from 0-3 minutes had the highest engagement rate. Shorter videos can also be planned and properly executed thereby making a good impact on the students. It is recommended that instructors should have video segments of ideally less than 6 minutes.

- Videos with talking heads of professors (where professors are shown) are more engaging than videos where no professor is shown. The professor's face provides a more personal touch to the video and removes the monotony of PowerPoint slides and lectures.

- Khan style video tutorials are more engaging. Khan style videos involve free hand sketching or drawing pictures/concepts on a blackboard while explaining a concept. Khan style videos allow professors to present themselves on the same level as the students rather than talking to them in a traditional teacher student lecture.

- Instructor speaking rate affects video engagement. Videos where tutors speak quickly with enthusiasm have more engagement.

- Students re-watched tutorials more frequently than lectures. Tutorials (i.e. procedural videos) are rather "how to" while lectures are conceptual.

The video production and video styles can affect the student engagement with the videos [7].

\section{H. Factors Related to Video Pre-production Planning and Production Phase}

The preproduction or planning phase of videos has a direct impact on the engagement of videos. Proper investment in the pre-production produces videos with better effect and engagement [7]. 
Partner organizations edit out professors' mistakes and help them navigate MOOC technicalities: computers, microphones, cameras, and lighting are coordinated to produce attention-grabbing videos [20]. During the recording of videos, instructors use the help of these partner organizations to polish their speech.

\section{Factors Related to Video Content, Quality and Related Materials}

In the research article "What Makes an Online Instructional Video Compelling?" [13], a study was conducted at the University of Columbia's online courses to find out which type of videos had most viewers and hits. To learn more about these videos, the analytics of the video hosting platform Kaltura were examined. Factors like number of video views, the average play-through rate (viewing time of video by student) were recorded. Interviews with students were conducted to learn about their learning experience. The following observations were found after studying the videos that had maximum viewers.

- Videos with a direct connection to the course assignments have usually higher views. Students re-watch the same video many times while taking assignments.

- Videos with the professor's wit and humour were the most watched.

- Sophisticated, high quality, professional looking videos with visuals and artefacts were the most engaging.

\section{J. Factors Related to the Video Distribution Channel}

YouTube is a predominant resource for video sharing. Channels let you explore YouTube rather as a social network than as a simple video database. Viral videos are videos that become popular through sharing videos and links through social networking sites, blogs, emails and instant messaging. Research shows that many videos went viral through YouTube [21]. The reason behind the videos' receiving a large number of viewers lies in the social networking feature of the website. Linking, rating, sharing and favourite features of YouTube make videos popular in an organic way. Khan Academy's first Math video went viral on YouTube in 2006 and it reached an audience of two million single students a month [22].

Khan Academy has all its videos posted on YouTube. It has 18 channels that group the videos according to their topics and language settings, for example Khan Academy projects, Khan Academy medicine, Khan Academy Hindi, Khan Academy Español [11]. As per YouTube strategy video channels provide lot of features to engage the customers. The channels can be optimized for placement in search, related channels, browse channels, and fed to engage current and potential customers across YouTube [23]. In July 2014, Khan Academy's YouTube network has 65 channels, and 2,073,463 total subscribers. There are currently 32,296 videos and the overall view count is 454,179,409 [11].

MOOCs like Coursera, edX have their own channels on YouTube where they showcase the learning videos. Along with the videos they give the link to the course website to sign up and participate in the course. Through the channels, users can also share the links of the videos on social networking channels like Facebook, Twitter, Google Plus etc [24] [25].

\section{K. Factors Related to Social Media and Networking}

Community participation on social network, such as on Twitter and Facebook, leads to the phenomenon of viral videos. Videos go viral when individuals or groups of people share a video with a huge group of people which in turn share it with other groups and communities, and so on, creating a chain reaction. The video is thus watched by a massive audience over a period of time, making it viral [26].

The online learning platforms and MOOC like Khan Academy, Coursera and edX are also present in the social networking platforms like Facebook, Google and Twitter [27] [28] [29] and benefit from the advantages. In a recent research in the year 2013, one of the Coursera courses was promoted through social media [30]. The course "Elearning and Digital Culture" of the University of Edinburgh was taken by 40,000 students from every continent. Prior to the course, instructors sent encouraging emails suggesting students to connect among each other via Google, Twitter and personal blogs. From there, students created further groups on more social media platforms, and communications went viral. The key learning spaces established were Facebook, Twitter, G+, blogs, and other media. These platforms allowed students to interact and share video links and other materials through a huge amount of interaction.

\section{Factors Related to Gamification}

Gamification is the use of game elements in a non-game context [31]. Gamification concepts can motivate people to engage with the content of a video or a course to build a vibrant community of participation. Gamification is about using data driven techniques used by game designers, and transferred to other digital environments to make them more engaging and drive experiences to make them viral. By using gamification concepts in a course, students get motivated and spend more time on interacting with the information, and enjoy the experience provided by the learning platform. Gamification is based on the following concepts: to capture user attention, and to use big data to generate valuable information to motivate the users [32][33].

Khan Academy uses gamification concepts to motivate students. The Khan academy rewards its students with different badges if they engage more with the video content, take quizzes, and challenge themselves for learning. The academy courses have instant feedback and cumulative feedback that are fundamental concepts of game design. The achievement milestones of students are shared in the community. The Khan Academy provides instant statistics about what the user has learned and the time spent on content. Users can drill down to minute data and track their progress [35] [36].

Gamification concepts can be used to increase views of videos. Successful attempts have been made to increase the views of videos by giving points and the use of game elements to create a viral experience [36] [33]. The gamification concepts can be applied to MOOC platforms to increase their video views and engagement.

\section{Factors Related to Mobile Format}

The term mobile learning refers to the use of mobile and hand-held devices such as smart phones, laptops and tablet PCs in the delivery of teaching and learning. Recently applications have come to market that are used for work- 
place learning, teaching and social networking. Mobile learning combines mobile computing with e-learning. The new mobile technologies offer huge potential in terms of flexibility and customization to individual needs. Students in this context expect training that is "just in time, just enough and just for me". In spite of mobile learning's recent development it enjoys high popularity among university students globally [37].

From a technology point of view mobile devices have become more capable of performing all necessary functions in e-learning. With mobile learning, learning can happen any place and any time as per user's convenience [38].

The Mobi MOOC course [40] has been aimed at mobile learning and is available through mobile devices. Participants use mobile devices during Mobi MOOC to interact with the course materials. Nearly $70 \%$ of the participants preferred to use mobile devices to access the course as it gave them flexibility of place and time to take the course. The course is also integrated in social platforms that brought mobile learning and social media together. With mobile device, learning environment is enhanced and the ability to share knowledge through online discussion is strengthened through social media.

In a recent survey it has been found that mobile video viewing was increased because of the rise of larger screen phones, 4G networks and better video quality [40]. Many mobile video apps have come to market which increase online engagement [41]. Mobile apps are available on the market that let you access MOOC videos through iPhones and smart phones. MOOC platforms have also taken to mobile learning. There are Khan Academy apps that let you access, search and organize the Khan Academy videos on your smart phone and iPad. [42] [43]. MOOC platforms like Coursera, Udemy, and Udacity also provide mobile apps for viewing video lectures [44] [45] [46].

YouTube also provides high quality video viewing on mobile devices [47].

\section{N. Factors Related to Multi-language Support}

MOOC and online learning platforms offer videos in many global languages and language subtitles. Khan Academy wants to make their videos widely available. Khan Academy offers videos which are dubbed into the major global languages of the world along with video subtitles and website translations [48]. Coursera also offers courses and videos in multiple languages along with subtitles [49]. YouTube states adding language specific captions, and dedicated channels for multiple languages can attract a wide audience [50].

\section{RESEARCH}

The papers that were analysed in the previous chapter do not give an overview of the topic containing all the factors. Mostly they focus on one particular group of factors, e.g. video content [10], video design and production [13], or student engagement [7].

Following the literature, we have identified factors that have direct or indirect effects on the online success in various categories. However, without a classified categorization there are some drawbacks. The video production must apply most, if not all, of the factors in harmony to be able to create a compelling video experience. It is necessary to provide a high-level design and a production guide- line with all the factors contained in the topic in order to manage and create better and more engaging online learning videos.

To give an answer to the identified issue, this research work follows the design methodology. The factors observed during the literature review are analyzed and translated into a complex framework. The main goal is to provide a simple, yet condensed overview - respectively a categorization of factors - that helps the video production to follow a clear path during the planning and shooting phase to make online learning videos within MOOCs successful.

\section{Results And Evaluation}

On the basis of the study of available literature, learning videos and websites, related success factors are classified into categories and presented in a condensed format. The main goal of this research is to generate the following artifacts:

- Categorization/classification of the success factors

- High-level conceptual overview of the categories

Detailed framework/guidelines for online learning video successThe success factors are classified on the basis of video content/style, support material, production phase, distribution medium, social media, gamification concepts, mobile technology and internationalization. The factors and corresponding categories that have been presented in Table 1. are placed in a list. However, the categories are inter-connected and affecting each other at various stages of video production. In order to provide a condensed overview, the current list view needs to be rearranged and visualized in a graph. Multiple categories can be combined to manage a video. When these factors are combined effectively, it can enhance the video engagement and views. For example: Good quality, multi-lingual videos can be hosted on YouTube channels [50] [23] or YouTube provides mobile video support and allows to share videos on social media platforms [50] [52].

The detailed study of the combination of the categories for the success of online learning videos is not in the scope of this research paper. The research team draws attention to the possibility of these combinations with a graphic visualization in the form of a spider graph in Fig. 1. Spider graphs [53] are used as a method of visualization that helps understand the relationship of multivariate data. Each axis represents a category with detailed factors that correspond to the group. The outer circumference could be manipulated to be able to show the qualitative strengths of the video production as a concept.

The evaluation for the proposed guidelines and artefacts is conducted in two ways. In the first part, the identified success factors have been verified by studying two specific popular learning video platforms namely Khan Academy and Coursera. Fig. 1 contains these success factors related to the online learning videos. By observing the video characteristics on MOOC websites, YouTube and social media like Facebook, Twitter, etc. It can be seen that almost all factors discussed in the paper are observed in both platforms except the factors related to gamification which are only observed in Khan Academy. The guidelines and the spider graphs have the potential to be useful from the video production perspective. The speaker, project manager and 
video director can use these artefacts as a checklist or concept document during the planning phase.

\section{CONCLUSION AND OUTLOOK}

This paper provides an insight into the research area related to the popularity of learning videos of MOOC platforms. It attempts to recognize and contribute to the debate raised during the research work on the topic of identifying the success factors of online learning videos. It provides a condensed overview of the categories in the form of the design artefacts as seen in Fig. 1. Video producers can use these artefacts as guidelines to support the online learning video production and conceptual development. Furthermore, it is evident from the framework that the categorized factors are not isolated from each other. They can be combined to have a positive impact on the video production and maintenance. The analysis of the synergy between them is not part of the current research scope.

The current research work has a few shortcomings that need to be addressed in future. The findings are based on the qualitative analysis of small samples of secondary data from scientific papers, articles, websites, and videos. Moreover, technology is changing at a faster rate. New techniques and trends, such as gamification, have recently been introduced in MOOC platforms. It is essential to do a detailed study for these upcoming trends. A detailed study of the synergy between categories should be persisted on in further research activities.

\section{REFERENCES}

[1] M. B. Wieling and W. H. A. Hofman, "The impact of online video lecture recordings and automated feedback on student performance," Comput. Educ., vol. 54, no. 4, pp. 992-998, 2010 http://dx.doi.org/10.1016/j.compedu.2009.10.002

[2] D. Zhang, L. Zhou, R. O. Briggs, and J. F. Nunamaker, "Instructional video in e-learning: Assessing the impact of interactive video on learning effectiveness," Inf. Manag., vol. 43, no. 1, pp. 15-27, 2006. http://dx.doi.org/10.1016/j.im.2005.01.004

[3] J. Borup, R. E. West, and C. R. Graham, "Improving online social presence through asynchronous video," Internet High. Educ., vol. 15 , no. 3, pp. 195-203, 2012. http://dx.doi.org/10.1016/j.iheduc. 2011.11 .001

[4] A. Cross, M. Bayyapunedi, D. Ravindran, E. Cutrell, and W. Thies, "VidWiki: Enabling the Crowd to Improve the Legibility of Online Educational Videos," 2014.

[5] L. Pappano, "The Year of the MOOC," The New York Times, pp. $1-7,2012$.

[6] D. Cathy, "What Was the First MOOC?," 2013. [Online]. Available: http://www.hastac.org/blogs/cathy-davidson/2013/09/27/whatwas-first-mooc. [Accessed: 29 May 2014].

[7] Guo, P.J., Kim, J., \& Rubin, R. "How video production affects student engagement: an empirical study of MOOC videos," Proceedings of the first ACM conference on Learning @ scale conference, 2014. [Online]. http://dl.acm.org/ft gateway.cfm?id=256 $6239 \& \mathrm{ftid}=1434762 \& \mathrm{dwn}=1$ $\&$ CFID $=323292369 \&$ CFTOKEN $=64850224$. [Accessed: 19 April 2014].

[8] CBS News, "Khan Academy: The future of education?," 2012. [Online]. Available: http://www.youtube.com/watch?v=zxJgPHM $5 \mathrm{~N}$ YI. [Accessed: 06 June 2014].

[9] Khan Academy, "Voice and Audiences," 2013. [Online]. Available: http://www.slideshare.net/mmark2/khanacademy-voice-and. [Accessed: 05 May 2014].

[10] L. Breslow, D. Pritchard, J. DeBoer, G. Stump, A. Ho, and D. Seaton, "Studying learning in the worldwide classroom: research into edX's first MOOC," Res. Pract. Assess., vol. 8, pp. 13-25, 2013
[11] Youtube, "Youtube - Khan Academy," 2014. [Online]. Available: http://www.youtube.com/user/khanacademy/about. [Accessed: 08 July 2014].

[12] Khan Academy, "Khan Academy," 2014. [Online]. Available: https://www.khanacademy.org/. [Accessed: 08 June 2014].

[13] M. Hibbert, "What Makes an Online Instructional Video Compelling?," 2014. [Online]. Available: http://www.educause.edu/ero/ article/what-makes-online-instructional-video-compelling [Accessed: 08 June 2014].

[14] M. Waldrop, "Massive open online courses transform higher education and science," 2013. [Online]. Available: http://www.scientificamerican.com/article/massive-open-onlinecourses-transform-highereducation-and-science/. [Accessed: 29 May 2014].

[15] Khan Academy, "Intelligent design and evolution video," 2008. [Online]. Available: http://www.youtube.com/watch? $\mathrm{v}=\mathrm{qxOEz} 9$ aPZNY \& feature $=$ share \&list $=$ PL7A9646BC5110CF64\&index $=3$. [Accessed: 10 July 2014].

[16] Coursera, "Social and Economic Networks: Models and Analysis,"

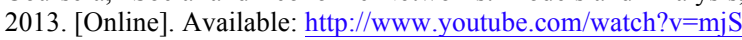
81EoBQOU\&list=PLVext98k2evjTlUe-C3HquUGRRVvRUyyk. [Accessed: 8 May 2014].

[17] Youtube, "Popular videos," 2014. [Online]. Available: http://www. youtube.com/channel/UCF0pVplsI8R5kcAqgtoRqoA. [Accessed: 29 May 2014].

[18] Youtube, "YouTube Analytics," 2014. [Online]. Available: https://www.youtube.com/analytics. [Accessed: 30 May 2014].

[19] B. Honigman, "8 Ways to Track YouTube Video Performance," 2012. [Online]. Available: http://www.socialmediaexaminer.com/ youtube-video-performance/. [Accessed: 30 May 2014].

[20] A. Meixler, "From Good to Great: What Is the Key to MOOC Success?," 2013. [Online]. Available: https://iversity.org/blog/ from-good-to-great-what-is-the-key-to-mooc-success/. [Accessed: 06 June 2014].

[21] T. Broxton, Y. Interian, J. Vaver, and M. Wattenhofer, "Catching a Viral Video,” 2010 IEEE Int. Conf. Data Min. Work., pp. 296-304, 2010. http://dx.doi.org/10.1109/icdmw.2010.160

[22] S. Khan, "Free learning videos go viral," 2011. [Online]. Available: http://edition.cnn.com/2011/OPINION/07/24/khan.video.lear ning/. [Accessed: 06 June 2014].

[23] Youtube Channel, "YouTube Channel Optimization," 2014. [Online]. Available: http://www.youtube.com/yt/playbook/channeloptimization html. [Accessed: 06 June 2014].

[24] Y. Coursera, "Coursera Youtube," 2014. [Online]. Available: http://www.youtube.com/user/coursera. [Accessed: 06 June 2014].

[25] Y. EdX, “EdX YouTube," 2014. [Online]. Available: http://www.youtube.com/user/EdXOnline. [Accessed: 06 June 2014].

[26] K. Alloca, "Why videos go viral," 2011. [Online]. Available: http://www.ted.com/talks/kevin allocca why videos go viral\#t2236 96. [Accessed: 06 June 2014].

[27] C. Facebook, "Facebook - Coursera," 2012. [Online]. Available: https://www.facebook.com/Coursera. [Accessed: 06 June 2014].

[28] C. Google Plus, "Google Plus," 2012. [Online]. Available: https://plus.google.com/+Coursera/posts. [Accessed: 06 June 2014].

[29] C. Twitter, "Twitter Coursera," 2011. [Online]. Available: https://twitter.com/coursera. [Accessed: 06 June 2014].

[30] E. Purser, A. Towndrow, and A. Aranguiz, "From the field Realising the Potential of Peer-to-Peer Learning: Taming a MOOC with Social Media Authors," sLearning Pap., vol. 33, pp. 1-5, 2013.

[31] S. Deterding, R. Khaled, L. Nacke, and D. Dixon, "Gamification: Toward a Definition," in Chi 2011, 2011, pp. 12-15.

[32] J. Hamari, J. Koivisto, and H. Sarsa, "Does Gamification Work? A Literature Review of Empirical Studies on Gamification," in Proceedings of the 47th Hawaii International Conference on System Sciences, 2014, pp. 1-10. http://dx.doi.org/10.1109/hicss.2014.377

[33] R. Paharia, "Can You Architect Virality? Absolutely. Here's How,” 2014. [Online]. Available: http://www.huffingtonpost.com/ 
rajat-paharia/can-you-architect-viralit b 5064073.html. [Accessed: 31 May 2014].

[34] Khan Academy, "About Khan Academy," 2014. [Online]. Available: https://www.khanacademy.org/about. [Accessed: 05 June 2014].

[35] H. Jacobson, "Gamification in Marketing: Lessons from the Khan Academy Website," 2013. [Online]. Available: http://searchengine watch.com/article/2303233/Gamification-in-Marketing-Lessonsfrom-the-Khan-Academy-Website. [Accessed: 31 May 2014].

[36] ISCEBS, "increase employee engagement with games," 2013.

[37] C. Giousmpasoglou and E. Marinakou, "The future is here: mlearning in higher education," 2013.

[38] M. O. M. El-hussein and J. C. Cronje, "Defining Mobile Learning in the Higher Education Landscape Research method," Educ. Technol. Soc., vol. 13, pp. 12-21, 2010.

[39] I. deWaard, S. Abajian, M. S. Gallagher, R. Hogue, N. Keskin, A. Koutropoulos, and O. C. Rodriguez, "Using mLearning and MOOCs to Understand Chaos, Emergence, and Complexity in Education," Int. Rev. Res. Open Distance Learn., vol. 12, no. 7, pp. 94-115, 2011.

[40] M. Katz, "Mobile Video Consumption Rising; Increase in Smartphone Usage in the U.S. - Appboy Weekly 7," 2014. [Online]. Available: http://blog.appboy.com/2014/04/mobilevideo-consumption-rising-increase-smartphone-usage-us-appboyweekly-7/. [Accessed: 09 June 2014].

[41] M. Edelstein, "5 Mobile Video Apps to Boost Online Engagement," 2013. [Online]. Available: http://www.socialmediaexaminer.com/5-mobile-video-apps-toboost-online-engagement/. [Accessed: 09 June 2014].

[42] K. App, "Khan Academy," 2014. [Online]. Available: http://khanapp.com/. [Accessed: 31 May 2014].

[43] K. Android, "KhAndroid," 2014. [Online]. Available: https://play.google.com/store/apps/details?id=org.khanacademy.vid eos. [Accessed: 31 May 2014].

[44] Coursera, "Coursera Homepage," 2014. [Online]. Available: https://www.coursera.org/. [Accessed: 08 June 2014].

[45] Udemy, "Udemy mobile," 2014. [Online]. Available: https://www.udemy.com/mobile/. [Accessed: 19 June 2014].

[46] Udacity, "Udacity mobile," 2014. [Online]. Available: https://www.udacity.com/mobile. [Accessed: 19 June 2014].

[47] Youtube, "Youtube Devices," 2014. [Online]. Available: https://www.youtube.com/yt/devices/. [Accessed: 09 June 2014].

[48] A. Khan, "Is Khan academy languages," 2014. [Online]. Available: https://khanacademy.zendesk.com/hc/en-us/articles/202460864-IsKhan-Academy-available-in-other-languages- [Accessed: 31 May 2014].

[49] Coursera, "Coursera Language support," 2014. [Online]. Available: http://help.coursera.org/customer/portal/articles/662076-do-your- lecture-videos-have-subtitles-closed-captions-. [Accessed: 05 June 2014].

[50] Youtube, "Youtube reaching all audiences," 2014. [Online]. Available: http://www.youtube.com/yt/playbook/reaching-allaudiences.html. [Accessed: 05 June 2014].

[51] Y. Chou, "Octalysis: Complete Gamification Framework," 2014. [Online]. Available: http://www.yukaichou.com/gamificationexamples/octalysis-complete-gamificationframework/\#.U6RRmPmSwXs. [Accessed: 20 June 2014].

[52] Youtube, "Youtube - build your community," 2014. [Online]. Available: https://www.youtube.com/yt/playbook/build-yourcommunity.html. [Accessed: 30 June 2014].

[53] Chambers, John, William Cleveland, Beat Kleiner, and Paul Tukey, "Graphical Methods for Data Analysis", 1983. [Online]. http://www.itl.nist.gov/div898/handbook/eda/section3/starplot.htm [Accessed: 10 July 2014].

\section{AUTHORS}

Safak Korkut is with the University of Applied Sciences and Arts Northwestern Switzerland, School of Business, Institute for Information Systems, Peter Merian-Strasse 86, 4052, Basel, Switzerland (email: safak.korkut@fhnw.ch)

Rolf Dornberger is with the University of Applied Sciences and Arts Northwestern Switzerland, School of Business, Institute for Information Systems, Peter MerianStrasse 86, 4052, Basel, Switzerland (email: rolf.dornberger@fhnw.ch)

Prajakta Diwanji is with the University of Applied Sciences and Arts Northwestern Switzerland, School of Business, M.Sc. Program in Business Information Systems. (email: prajakta.diwanji@students.fhnw.ch)

Bindu Puthur Simon is with the University of Applied Sciences and Arts Northwestern Switzerland, School of Business, M.Sc. Program in Business Information Systems. (email: bindu.puthur@students.fhnw.ch)

Michael Märki is with the University of Applied Sciences and Arts Northwestern Switzerland, School of Business, M.Sc. Program in Business Information Systems. (email michael.maerki@students.fhnw.ch)

This article is an extended and modified version of a paper presented at the the Interactive Mobile and Computer Aided Learning (IMCL2014), held in November 2014, in Thessaloniki, Greece. Manuscript received 11 Febryary 2015. Published as resubmitted by the authors 20 August 2015. 